\title{
Sports-related dermatoses among road runners in Southern Brazil ${ }^{*}$
}

\author{
Kátia Sheylla Malta Purim ${ }^{1}$
}

Neiva Leite ${ }^{2}$

DOI: http://dx.doi.org/10.1590/abd1806-4841.20142792

\begin{abstract}
BACKGROUND: Road running is a growing sport.
ОвјестіVES: To determine the prevalence of sports-related dermatoses among road runners.

METHODS: Cross-sectional study of 76 road runners. Assessment was performed by means of a questionnaire, interview, and clinical examination. The chi-square and linear trend tests were used for analysis.

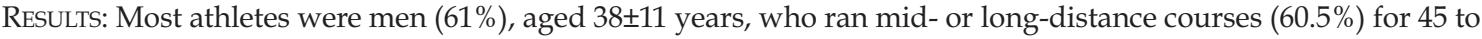
60 minutes $(79 \%)$, for a total of $25-64 \mathrm{~km}(42.1 \%)$ or more than $65 \mathrm{~km}(18.4 \%)$ per week. The most prevalent injuries were blisters $(50 \%)$, chafing $(42.1 \%)$, calluses $(34.2 \%)$, onychomadesis $(31.5 \%)$, tinea pedis $(18.4 \%)$, onychocryptosis $(14.5 \%)$, and cheilitis simplex $(14.5 \%)$. Among athletes running $>64 \mathrm{~km}$ weekly, several conditions were significantly more frequent: calluses $(\mathrm{p}<0.04)$, jogger's nipple $(\mathrm{p}<0.004)$, cheilitis simplex $(\mathrm{p}<0.05)$, and tinea pedis $(\mathrm{p}<0.004)$. There was a significant association between the weekly running distance and the probability of skin lesions. Of the athletes in our sample, $57 \%$ trained before 10 a.m., $86 \%$ wore clothing and accessories for sun protection, $62 \%$ wore sunscreen, and $19.7 \%$ experienced sunburn. Traumatic and environmental dermatoses are common in practitioners of this outdoor sport, and are influenced by the weekly running distance.

CONCLUSION: In this group of athletes, rashes, blisters, sunburn, and nail disorders were recurrent complaints regardless of running distance. Calluses, athlete's foot, chapped lips, and jogger's nipple predominated in individuals who ran longer routes.
\end{abstract}

Keywords: Athletes; Quality of life; Running; Dermatology

\section{INTRODUCTION}

Road running is growing in popularity due to its accessibility and multiple health benefits. However, as do all sports, it exposes practitioners to a variety of factors that predispose to the development of dermatoses during training or competition. ${ }^{1-4}$ These factors include exposure to sunlight, frequent impact, friction of the skin against shoes and clothing, soft-tissue trauma (particularly of the lower limbs), moisture and limited ventilation of skinfolds, and cracked and fissured skin, as well as external factors such as falls, collisions, wounds, contact with irritant plants, animals, inclement weather, and geographic and seasonal hazards. ${ }^{1,25-11}$

Research shows that the most common lesions of track and field athletes affect the skin, given its essential role in the defense of the body as a physical barrier. ${ }^{1-3}$ These dermatoses may be classified etiologically as infectious, inflammatory, traumatic, or environmental. ${ }^{3,45,6,7}$ The most common infectious causes are fungi (tinea pedis), Gram-positive bacteria, and viruses (plantar warts) ${ }^{8,9}$ Sports-related infections can be a major cause of morbidity, whether individually or affecting whole teams. ${ }^{2}$ Macaulay et al. suggest that vigilance of skin lesions in the sport setting is important on the part of athletes, trainers, coaches, and other sports medicine professionals. ${ }^{12}$

Among inflammatory causes, contact dermatitis, urticaria, and - rarely - exercise-induced anaphylaxis are the most common. Traumatic conditions include "jogger's toe" (also known as "black toenail"), characterized by bleeding in the nail matrix and periungual region; "runner's purpura" (exercise-induced purpura), which affects the lower limbs and the face; foot blisters and calluses; and "jogger's nipple". 1,2,13-16 The main environmental conditions are first- and second-degree sunburn and malignant and premalignant skin lesions, but may also include frostbite, lesions caused by contact with salt water, and injuries caused by animals and plants. ${ }^{1,4,17-20}$

Received on 19.05.2013.

Approved by the Advisory Board and accepted for publication on 03.10.2013

* Work performed at the Department of Dermatology, Universidade Positivo (UP) Medicine Program, in partnership with the Quality of Life Research Center, Department of Physical Education, Universidade Federal do Paraná (UFPR) - Curitiba (PR), Brazil.

Financial Support: None

Conflict of Interest: None

Universidade Positivo (UP) - Curitiba (PR), Brazil.

Universidade Federal do Paraná (UFPR) - Curitiba (PR), Brazil.

(C2014 by Anais Brasileiros de Dermatologia

An Bras Dermatol. 2014;89(4):587-92. 
The literature on skin lesions in runners is scarce, and studies are usually limited to specific modalities of running, which precludes the use of their data for runners in general. ${ }^{6,15,20,21}$ Mailler et al. conducted a review of several studies on dermatological injuries occurring on marathon day in athletes running 15 different marathons, and found that the most common lesions were blisters and other injuries from repetitive friction $(0.2-39 \%)$, followed by jogger's nipple $(2-16.3 \%)$ and chafing and abrasions $(0.4-16 \%) .{ }^{15}$

Ambros-Rudolph et al. found a correlation between increased risk of skin cancer and outdoor running, and suggested that runners adopt behavioral protection measures, such as running outside of peak radiation hours, wearing protective sportswear designed to cover the largest body area possible, and, particularly, adequate and systematic sunscreen use. ${ }^{19}$

The growing popularity of running and the risk of dermatological injuries it carries justify and highlight the need for specific data geared at this sport and its practitioners, both professional and amateur, who may not fit the risk factor exposure limits to which elite athletes - who are usually the object of research are willing to subject themselves. Within this context, the purpose of the present study is to assess the prevalence of skin lesions among road runners in a large Brazilian city.

\section{MATERIALS AND METHODS}

This descriptive, cross-sectional epidemiological study was carried out from February to June 2012 with the objective of assessing the occurrence of sports-related dermatoses among road runners in a Brazilian city. The sample comprised adults (age $>18$ years) of both sexes who were regular practitioners of road running. Individuals who did not meet these criteria and those who were involved in other sports were excluded from the sample, as were those who refused to participate.

We employed a purposive nonprobability sampling strategy. Athletes were approached on the day before competitions. Participants agreed to join the study sample after reading and understanding an informed consent form and providing written consent for data use. The project was approved by the relevant Research Ethics Committee (protocol number 055/2011).

For the purposes of this study, road running was defined in accordance with International Association of Athletics Federation (IAAF) rules as the sport of racing on made-up roads (streets, avenues, highways, etc.) along standard distances of 5 to $100 \mathrm{~km} .{ }^{22}$ Athletes' weekly running distances were stratified into three categories: $\leq 24 \mathrm{~km}, 25-64 \mathrm{~km}$, and $\geq 65 \mathrm{~km}$.

Each athlete was interviewed with a structured questionnaire consisting of closed-ended questions in easy-to-understand language devised specifically for this study, and designed to collect information on sociodemographic and training variables, medical history, sun protection and skincare practices. Each participant also underwent a physical examination, which was documented photographically. The data collection instrument was previously tested and checked by two experienced running coaches to ensure its adequacy, comprehension, and ability to collect the required data on athletes and their lesions.

Data were analyzed by means of descriptive statistics for sample characterization purposes and associational inferential statistics to determine risk factors for skin lesions. The chi-square test and test for linear trend were used to test for associations between skin lesions and weekly running distance (in $\mathrm{km}$ ). The significance level was set at $\mathrm{P}=0.05$.

\section{RESULTS}

A total of 80 road runners were approached to take part in the study. The combined refusal and attrition rate was $5 \%$. Therefore, the study population comprised 76 runners, of whom $61 \%$ were male and $39 \%$ were female, with a mean age of $38 \pm 11$ years. Most participants were white $(78 \%)$, and $75 \%$ had a higher education ( $28 \%$ undergraduate, $47 \%$ graduate). Overall, $83 \%$ of participants were from Southern Brazil (Table 1).

Middle- and long-distance running were the predominant activities (60.5\%); 30\% of respondents had been running for 1 to 3 years, $36 \%$ for 4 to 9 years, and $23 \%$ for more than 10 years. Approximately $36.8 \%$ ran 12 to $24 \mathrm{~km}$ per week, $42.1 \%$ ran 25 to $64 \mathrm{~km}$ per week, and $18.4 \%$ ran more than $65 \mathrm{~km}$ per week. Most athletes (79\%) trained for 45 to 60 minutes at a time, three or four times weekly $(51 \%)$ or five or six times weekly (40\%).

Approximately $41 \%$ of the respondents ran in municipal or state races, and only $8 \%$ ran at all available events. Overall, $55 \%$ of participants ran in municipal events, $36 \%$ in state events, $42 \%$ in national events, and $12 \%$ in international events. The frequency of participation was highly variable, but a plurality of respondents $(49 \%)$ took part in one race per month $(49 \%)$. Most respondents trained on the streets $(68 \%)$, but also on tracks, treadmills, dirt roads, and grasslands.

Regarding the footwear worn by respondents while training, most $(84 \%)$ alternated between one and three pairs of running shoes (84\%), which were usually replaced after 3 to 10 months of use (55\%). Most participants $(76 \%)$ wore their running shoes for 1 to 3 hours a day $(76 \%)$, and wore the same size $(50 \%)$ or one size up from their usual non-athletic shoes (45\%). Over half of participants (55\%) reported discomfort caused by running shoes, including pain and injury, but only $29 \%$ wore protective accessories while training. 
TABLE 1: Absolute and relative frequencies of qualitative sociodemographic variables

\begin{tabular}{lll}
\hline & Absolute frequency & Relative frequency \\
\hline Sex & 46 & $61 \%$ \\
Male & 30 & $39 \%$ \\
Female & & \\
Skin color (race/ethnicity) & 59 & $78 \%$ \\
White & 3 & $4 \%$ \\
Black & 10 & $13 \%$ \\
Brown & 4 & $5 \%$ \\
Yellow & & $5 \%$ \\
Educational attainment & 4 & $17 \%$ \\
Secondary & 13 & $28 \%$ \\
Higher, some & 21 & $47 \%$ \\
Higher, undergraduate & 36 & $2 \%$ \\
Higher, graduate & 2 & $83 \%$ \\
Not reported & & $12 \%$ \\
Region of origin & 63 & $5 \%$ \\
$\quad$ South & 9 & 4 \\
Southeast & 4 & \\
Other regions & & \\
\hline
\end{tabular}

TABLE 2: Absolute and relative frequencies of qualitative variables concerning protection from sunlight while running

\begin{tabular}{llcc}
\hline & & Absolute frequency & Relative frequency \\
\hline Usual training time & Before 10 a.m. & 43 & $57 \%$ \\
& 10 a.m.-4 p.m. & 11 & $14 \%$ \\
& After 4 p.m. & 30 & $39 \%$ \\
Clothing and accessories & Sunglasses & 35 & $46 \%$ \\
worn for protection & Hat/visor & 65 & $86 \%$ \\
& T-shirt/jersey & 65 & $86 \%$ \\
& (short- or long-sleeved) & & $21 \%$ \\
\hline
\end{tabular}

The most common sports-related dermatoses in the sample were blisters (50\%), chafing $(42.1 \%)$, calluses $(34.2 \%)$, onychomadesis $(31.5 \%)$, sunburn $(19.7 \%)$, tinea pedis $(18.4 \%)$, onychocryptosis $(14.5 \%)$, cheilitis simplex (14.5\%), insect stings (7.9\%), cuts and abrasions $(6.5 \%)$, piezogenic pedal papules $(3.9 \%)$, and calcaneal petechiae $(2.6 \%)$. One athlete had several actinic keratoses $(1 \%)$ and reported a personal history of basal cell carcinoma.

Regarding the timing of sun exposure, most athletes trained before 10 a.m. (57\%) or after 4 p.m. $(39 \%)$. Protective measures worn by the participants included caps, hats, or visors $(86 \%)$ and short- or longsleeved shirts and jerseys (86\%). Only $46 \%$ wore sunglasses, and $21 \%$ wore tights or pants (Table 2).

Regarding sunscreen use, $62 \%$ of athletes use sunscreen one to three times, but $28 \%$ do not wear it at all. The main body areas to which sunscreen is applied were the face $(72 \%)$, nose $(55 \%)$, and ears $(41 \%)$; less than $40 \%$ of respondents use sunscreen elsewhere on their bodies. Most sunscreen users (53\%) wear products with an SPF $>30$ rating (Table 3).

Analysis of the distribution of skin conditions revealed that the categories "calluses", "jogger's nip- ple", and "cheilitis simplex" were significantly more common among athletes with longer weekly running distances $(p<0.05)$. Calluses were more common in the $\geq 65 \mathrm{~km}$ category $(64.3 \%)$, as were jogger's nipple $(35.7 \%)$, cheilitis simplex $(35.7 \%)$, and tinea pedis (50\%). Among the remaining dermatoses, chafing (57.1\%), blisters $(64.3 \%)$, onychocryptosis $(28.6 \%)$, onychomadesis $(50 \%)$, herpes labialis $(14.2 \%)$, and insect stings (14.2\%) were also more common among athletes running $\geq 65 \mathrm{~km}$ per week. Sunburn occurred in all distance categories, with no significant differences among them (Table 4).

Testing for linear trend revealed associations between running distance and several cutaneous lesions, including calluses $(\mathrm{p}=0.024)$, onychocryptosis $(p=0.034)$, onychomadesis $(p=0.030)$, tinea pedis $(p=0.011)$, jogger's nipple $(p=0.002)$, and cheilitis simplex $(p=0.034)$, suggesting that the likelihood of these injuries increases with the weekly running distance.

\section{DISCUSSION}

During the last decade, running and walking have become increasingly popular activities in a wide range of versions. Practitioners of these modalities, 
TABLE 3: Absolute and relative frequencies of qualitative variables regarding sunscreen use while running

\begin{tabular}{llcc}
\hline & Sunscreen use & Absolute frequency & Relative frequency \\
\hline Frequency of sunscreen use & $1 \mathrm{x}$ & 31 & $41 \%$ \\
& $2 \mathrm{x}$ & 6 & $8 \%$ \\
& $3 \mathrm{x}$ & 10 & $13 \%$ \\
Body regions to which & Does not wear sunscreen & 21 & $28 \%$ \\
sunscreen is applied & Face & 55 & $72 \%$ \\
& Ears & 31 & $41 \%$ \\
& Nose & 42 & $55 \%$ \\
& Lips & 16 & $21 \%$ \\
& Nape of neck & 27 & $36 \%$ \\
& Torso & 13 & $17 \%$ \\
Sun protection factor & Abdomen & 9 & $12 \%$ \\
& Limbs & 20 & $26 \%$ \\
& Dorsal aspect of hands & 25 & $33 \%$ \\
& SPF <15 & 2 & $3 \%$ \\
& SPF 15-25 & 18 & $24 \%$ \\
\hline
\end{tabular}

TABLE 4: Relative frequencies of cutaneous and mucosal conditions, infectious, hematomas, and other skin-related complaints, stratified by weekly running distance.

\begin{tabular}{|c|c|c|c|c|c|c|c|c|}
\hline & \multirow[t]{2}{*}{ Category } & \multicolumn{2}{|c|}{$\begin{array}{l}\leq 24 \mathrm{~km} \\
(\mathrm{n}=28)\end{array}$} & \multicolumn{2}{|c|}{$\begin{array}{l}25-64 \mathrm{~km} \\
(\mathrm{n}=32)\end{array}$} & \multicolumn{2}{|c|}{$\begin{array}{l}\geq 65 \mathrm{~km} \\
(\mathrm{n}=14)\end{array}$} & \multirow[t]{2}{*}{$\mathbf{P}^{*}$} \\
\hline & & n & $\%$ & $\mathbf{n}$ & $\%$ & n & $\%$ & \\
\hline \multirow{11}{*}{$\begin{array}{l}\text { Cutaneous and } \\
\text { mucosal conditions }\end{array}$} & Chafing & 11 & 39.3 & 13 & 40.6 & 8 & 57.1 & 0.163 \\
\hline & Blisters & 12 & 42.9 & 17 & 53.1 & 9 & 64.3 & 0.091 \\
\hline & Calluses & 8 & 28.6 & 9 & 28.1 & 9 & 64.3 & 0.024 \\
\hline & Onychocryptosis & 2 & 7.1 & 5 & 15.6 & 4 & 28.6 & 0.034 \\
\hline & Onychomadesis & 6 & 21.4 & 11 & 34.4 & 7 & 50 & 0.030 \\
\hline & Eczema & 0 & 0 & 1 & 3.1 & 0 & 0 & 0.397 \\
\hline & Boils & 1 & 3.6 & 1 & 3.1 & 1 & 7.1 & 0.323 \\
\hline & Ingrown hairs & 2 & 7.1 & 0 & 0 & 2 & 14.2 & 0.297 \\
\hline & Jogger's nipple & 1 & 3.6 & 2 & 6.2 & 5 & 35.7 & 0.002 \\
\hline & Conjunctivitis & 0 & 0 & 1 & 3.1 & 1 & 7.1 & 0.088 \\
\hline & Cheilitis simplex & 3 & 10.7 & 3 & 9.4 & 5 & 35.7 & 0.034 \\
\hline \multirow[t]{3}{*}{ Infections and hematomas } & Subungual hematoma & 2 & 7.1 & 2 & 6.2 & 0 & 0 & 0.190 \\
\hline & Herpes labialis & 1 & 3.6 & 2 & 6.2 & 2 & 14.2 & 0.108 \\
\hline & Tinea pedis & 4 & 14.3 & 3 & 9.4 & 7 & 50 & 0.011 \\
\hline \multirow[t]{5}{*}{ Other complaints } & Sunburn & 7 & 25 & 5 & 15.6 & 3 & 21.4 & 0.322 \\
\hline & Insect stings & 2 & 7.1 & 2 & 6.2 & 2 & 14.2 & 0.254 \\
\hline & Cuts and abrasions & 1 & 3.6 & 3 & 9.4 & 1 & 7.1 & 0.274 \\
\hline & Animal bites & 0 & 0 & 1 & 3.1 & 0 & 0 & 0.397 \\
\hline & Plant dermatitis & 2 & 7.1 & 1 & 3.1 & 1 & 7.1 & 0.432 \\
\hline
\end{tabular}

\section{* Test for linear trend}

whether for leisure, sport, or health benefits, are exposed to different hazards and injuries. ${ }^{1,27,8,22}$ The objective of this study was to investigate the most common dermatoses among road runners in a Brazilian city. This sample largely comprised white males between the third and fourth decades of life who ran middle- and long-distance races and frequently took part in competitive events.
Road running is a sport worthy of research interest given its importance within the current context and the diverse range of events, for amateur and professional athletes alike, held in different regions of the country. Competitive running entails permanent physical preparedness and several physiological demands if athletes are to reach the requisite physical performance while remaining healthy. ${ }^{21-23}$ The athletes 
who participated in the present study had a high level of educational attainment, which probably facilitated their access to information that helped them reach a higher level of physical fitness.

The athletes assessed in the present study combined road running with running on tracks, treadmills, dirt roads, and grasslands. Like marathon runners, they were thus subject to variations in terrain, cloud cover, weather, soil, and altitude, as well as systemic adaptations imposed by their training, such as type, volume, and intensity of exercise. ${ }^{2,18,21-23}$ Investigating the occurrence of lesions and their associations with skin- and training-related factors may contribute to a better understanding of the causal factors of dermatoses and related conditions, with a view to prevention. ${ }^{1,7,8,12,24}$ Furthermore, contact with animals and plants while training in rural settings may lead to polymorphic dermatitides of variable frequency and severity, differing from the common cutaneous conditions seen in private dermatology practice. ${ }^{4}$

Studies have shown that the typical lesions of long-distance runners affect the feet, and are mainly characterized by calluses and nail damage. ${ }^{6,13,14,15,20,25}$ In the present study, the feet were affected by blisters, calluses, onychomadesis, tinea pedis, onychocryptosis, piezogenic pedal papules, and calcaneal petechiae. These lesions are generally associated with internal and external factors, such as local trauma and excessive use of the lower extremities.

Fungal infections of the foot are common among athletes due to multifactorial conditions involving the infectious agent, as well as individual and environmental characteristics (such as heat and moisture) ${ }^{8,24,26}$ Subungual and periungual hematomas, both of which occurred in the participants of this study, were not statistically significant, but may lead to nail dystrophy and must be distinguished clinically and dermatoscopically from onychomycosis and, particularly, from acral melanoma. ${ }^{1,13,26}$

The high frequency of distribution of cutaneous lesions in the lower limbs observed in the present study reflects the great risk of sports-related conditions and injuries in sports involving activities during which the body is propelled forward by rapid leg and foot movements, leading to massive wear and trauma of these structures. These results are similar to those found in studies of marathon runners, soccer players, track and field athletes, and tennis players. ${ }^{6,8,14,15,20,21,26,27}$ In their study of 100 amateur road racers in the Brazilian city of Belo Horizonte, state of Minas Gerais, Ferreira et al. detected a $40 \%$ prevalence of musculoskeletal and joint lesions, although they did not specify anatomic location or skin status. ${ }^{23}$ Despite a male predominance, differences in the focus and methods of the study preclude detailed comparisons.
All athletes are vulnerable to a wide range of medical conditions that can be influenced by individual factors, sport-specific circumstances, peculiar characteristics of equipment worn or used, biomechanical factors, and physical demands. ${ }^{1-3,7,24}$ Blisters and calluses are, respectively, acute and chronic responses to the frequent mechanical traumas to which runners are subjected..$^{8,14,16}$ In the present investigation, these lesions may be attributed to repetitive friction, poor shoe fit, irregular ground surfaces, and inadequate skin protection, which are factors consistent with the literature. ${ }^{24}$

Competitive sports challenge practitioners to push their physical abilities to the limit, which may expose athletes to increased risk. In the present study, weekly running distance was associated with the presence of sports-related dermatoses. Athletes who ran longer distances per week were at greater risk of jogger's nipple than athletes who ran shorter total distances, probably due to friction resulting in irritation and contact with T-shirts or jerseys made from nylon or coarse fibers. ${ }^{1,27,8,28}$

Regarding sun protection practices, Bakos et al. found results similar to those of the present study, i.e., inadequate sunscreen use. ${ }^{17}$ The percent rate of sunburn reported in our sample must be interpreted with caution. Respondents may have been subject to recall bias and thus not remembered milder episodes of sunburn, or, conversely, due to reverse causation bias, may have increased their protection practices after a particularly severe episode. Another rationale involves the predominance of training outside peak sunlight hours (before 10 a.m. and after 4 p.m.) and the use of sportswear to keep body surfaces covered. It bears stressing that road runners also train and compete at night.

Sunburn is a biological marker of exposure to high-dose ultraviolet radiation, and is a major risk factor for the development of cutaneous neoplasms, including melanoma. ${ }^{17-19,29}$ Studies have reported exposure to excess doses of sunlight radiation in cyclists and increased risk of cutaneous carcinogenesis in marathon runners. ${ }^{1-3,8,30}$ Sports-related skin cancer is a little-known entity, perhaps due to the scarcity of records and to the difficulty of establishing a causal nexus, in view of the long latency period of these neoplasms and the presence of other mechanisms involved in the carcinogenesis process.

Studies have shown that individuals involved in outdoor sports are subject to the harmful cumulative effects of exposure to ultraviolet radiation, the intensity of which varies with altitude, latitude, season, atmospheric conditions, time of day, and photoprotection practices employed. ${ }^{1,17,18}$ In a tropical country such as Brazil, where intense exposure to sunlight 
is still the norm for sociocultural reasons, particular care is required. Therefore, photoprotection practices in sports should combine several methods: natural, physical (clothing and accessories), use of broad-spectrum sunscreen (providing UVB and UVA protection), a carotenoid- and antioxidant-rich diet, adequate timing of practice, and staying in the shade whenever possible to minimize exposure to sunlight. ${ }^{18,29}$

Limitations of this study include the small sample size, which precludes extrapolation of our findings to other regions of the country. Furthermore, the cross-sectional design and the decision to collect data during a competitive event may explain the higher frequency of cutaneous disorders due to trauma and friction, as well as the low prevalence of dermatoses of infectious origin. The relevance of the present study lies in its demonstration of the occurrence of preventable dermatoses and, particularly, in providing a warning about the need for broader and more consistent adoption of photoprotection practices in sport. ${ }^{1,18}$

\section{REFERENCES}

1. D'Acri AM, Bakos RM, Purim KSM. Dermatoses no esporte. In: Lupi O, Cunha PR Rotinas de diagnóstico e tratamento da Sociedade Brasileira de Dermatologia. 2 ed. Itapevi (SP): AC Farmacêutica; 2012. p.165-9.

2. Adams BB. Sports Dermatology. Cincinnati, Ohio: Springer; 2006.

3. Bender TW. Cutaneous Manifestations of Disease in Athlete. Skinmed. 2003;2:34-40.

4. Haddad Jr V. Identification of acute diseases caused by animals and plants in wild environments: contribution to dermatologic practice. An Bras Dermatol. 2009;84:343-8.

5. Heymann WR. Dermatologic problems of the endurance athlete. J Am Acad Dermatol. 2005;52:345-6.

6. De Luca JF, Adams BB, Yosipovitch G. Skin Manifestations of Athletes Competing in the Summer Olympics. Sports Med. 2012;42:399-413.

7. Kolbach MR, Cossio MLT, Santa Maria MLSP, Carreno NO, La Cruz C, Fajre XW. Dermatoses em los desportistas. Rev Med Chile 2008;136:249-55.

8. Mailler-Savage EA, Adams BB. Skin Manifestations of Running. J Am Acad Dermatol. 2006:55:290-301.

9. Metelitsa A, Barankin B, Lin AN. Diagnosis of sports related dermatoses. Int J Dermatol. 2004;43:113-9.

10. Pecci M, Comeau D, and Chawla V. Skin conditions in the athlete. Am J Sports Med. 2009;37:406-18.

11. Pharis DB, Teller C, Wolf JE. Cutaneous manifestations of sports participation. J Am Acad Dermatol. 1997;36:448-59.

12. sportsmed.org [Internet]. Macaulay AA, Levine WN. Skin care in athletes. Sports Medicine Update. July/August; 2010. p 2-5. [cited 2013 Apr 20]. Available from: http://www.sportsmed.org/

13. Adams BB. Jogger's toenail. J Am Acad Dermatol. 2003:48:S58-9.

14. Helm MF, N Helm T, F Bergfeld W. Skin problems in the long-distance runner 2500 years after the Battle of Marathon. Int J Dermatol. 2012;51:263-70.

15. Mailler EA, Adams BB. The Wear and Tear of 26.2 Dermatological injuries reported on marathon day. Br J Sports Med. 2004:38:498-501.

16. Basler RS, Hunzeker CM, Garcia MA. Athletic skin injuries: combating pressure and friction. Phys Sportsmed. 2004;32:33-40

17. Bakos RM, Wagner MB, Bakos L, Derose EH, Grangeiro Neto J.A. Queimaduras e hábitos solares em um grupo de atletas brasileiros. Rev Bras Med Esporte. 2006;12:275-8.

18. Purim KSM, Leite, N. Fotoproteção e exercício físico. Rev Bras Med Esporte. 2010;16:224-9.

19. Ambros-Rudolph CM, Hofmann-Wellenhof R, Richtig E, Müller-Fürstner M, Soyer HP, Kerl H. Malignant melanoma in marathon runners. Arch Dermatol. 2006;142:1471-4.

20. Brunet ME, Cook SD, Brinker MR, Dickinson JA. A survey of running injuries in 1505 competitive and recreational runners. J Sports Med Phys Fitness. 1990;30:307-15.
Further research involving standardization of records of skin lesions and conditions in similar populations of Brazilian athletes could aid the implementation of sports-related skin health programs, with a view to improved prevention, education, and management of cutaneous infections and diseases in athletes.

\section{CONCLUSION}

In this sample of road runners, blisters, calluses, chafing, nail disorders, sunburn, and chapped lips (cheilitis simplex) were common, recurrent dermatoses, regardless of running distance. On the basis of our findings, we may conclude that calluses, onychocryptosis, onychomadesis, athlete's foot, cheilitis simplex, and jogger's nipple are conditions associated with long-distance running, and should be prevented accordingly. In larger samples, other variables might have been statistically significant. $\square$

21. Pastre CM, Carvalho Filho G, Monteiro HL, Netto Jr J, Padovani CR, Garcia AB. Exploração de Fatores de Risco para Lesões no Atletismo de Alta Performance. Rev Bras Med Esporte. 2007;13:200-4.

22. laaf.org [Internet]. Associação Internacional das Federações de Atletismo. [aceso 10 Abr 2013]. Disponível em: http://www.iaaf.org

23. Ferreira AC, Dias JMC, Fernandes RM, Sabino GS, Anjos MTS, Felício DC. Prevalência e fatores associados a lesões em corredores de rua do município de Belo Horizonte, MG. Rev Bras Med Esporte. 2012;18:252-4.

24. Zinder SM, Basler RS, Foley J, Scarlata C, Vasily DB. National AthleticTrainers' Association Position Statement: Skin Diseases. J Athl Train. 2010;45:411-28.

25. Van Middelkoop M, Kolkman J, Van Ochten J, Bierma-Zeinstra SM, Koes BW. Risk factors for lower extremity injuries among male marathon runners. Scand J Med Sci Sports. 2008;18:691-7.

26. Purim KSM, Niehues LP, Queiroz-Telles FF, Leite N. Aspectos epidemiológicos das micoses dos pés em um time chinês de futebol. Rev Bras Med Esporte 2006;12:16-9.

27. Pluim BM, Staal JB, Jayanthi N. Tennis injuries: occurrence, aetiology and a prevention. Br J Sports Med. 2006;40:415-23.

28. Kockentiet B, Adams BB. Contact dermatitis in athletes. J Am Acad Dermatol. 2007:56:1048-55.

29. Gontijo GT, Pugliesi MCC, Araújo FM. Fotoproteção. Surg Cosmet Dermatol. 2009;1:186-92.

30. Moehrle M, Heinrich L, Schmid A, Garbe C. Extreme UV exposure of professional cyclists. Dermatology. 2000;201:44-5.

MAILING ADDRESS:
Kátia Sheylla Malta Purim
Universidade Positivo - Curso de Medicina
Rua Professor Pedro Viriato Parigot de Souza, 5.300
Campo Comprido
81280-330-Curitiba - PR
Brazil
E-mail:kspurim@gmail.com

MAILING ADDRESS:

Kátia Sheylla Malta Purim

Universidade Positivo - Curso de Medicina

Rua Professor Pedro Viriato Parigot de Souza, 5.300

Campo Comprido

Brazil

E-mail:kspurim@gmail.com

How to cite this article: Purim KSM, Leite N. Sports-related dermatoses among road runners in Southern Brazil. An Bras Dermatol. 2014;89(4):587-92. 